\title{
La autotextualidad como generadora de sentidos en "Prisión perpetua" de Ricardo Piglia
}

\author{
The autotextuality as a generator of meanings \\ in Ricardo Piglia's "Prisión perpetua"
}

\section{Mariano Hernández García*}

RESUMEN: En este artículo se analizan las relaciones literarias creadas a partir del entrecruzamiento formal y temático de las dos partes de la nouvelle "Prisión perpetua" de Ricardo Piglia. Se plantea la hipótesis de que la estrategia narrativa usada en la obra provoca un tipo de autotextualidad que, a la manera de dos espejos enfrentados, expande notablemente los sentidos de cada uno del par de capítulos que conforman el texto. Asimismo, la puesta en abismo y la fragmentación aparecen como los cimientos formales que permiten una lectura múltiple y compleja.

PalaBRaS Clave: Prisión perpetua, Autotextualidad, Puesta en abismo, Fragmentación.

ABSTRACT: In this article the author looks into the literary relationships created with the intertwining, both formal and thematic, of the two parts of Ricardo Piglia's nouvelle "Prisión perpetua" (Perpetual Prison). The author suggests that the strategy used in the narrative generates a kind of autotextuality that, as two opposing mirrors, expands significantly the meanings of each of the two chapters that constitute the piece of writing. Furthermore, the mise en abysme and fragmentation appear as the foundations that allow a multiple and complex reading.

KEY wORDS: Prisión perpetua, Autotextuality, Mise en abyme, Fragmentation.

Recibido: 9 de marzo, 2017

Aceptado: 18 de agosto, 2017

El Colegio de México (mhgacatlan@hotmail.com). 


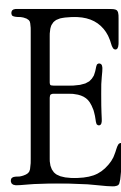

n 1992, la Coordinación de Humanidades de la unam publicó una antología de cuentos de Ricardo Piglia titulada Cuentos con dos rostros, la cual incluye cinco relatos: "En otro país", "El fluir de la vida", "La caja de vidrio", "El precio del amor", "La loca y el relato del crimen". Los cuentos "La caja de vidrio" y "El precio del amor", formaron parte de la primera edición de Nombre falso (1975); "La loca y el relato del crimen" se incluye en una edición posterior (1994). Por su parte, "En otro país" y "El fluir de la vida" tampoco eran textos inéditos; sin embargo, habían aparecido no como relatos separados y autónomos, sino como las dos partes que conformaban una misma obra, la nouvelle "Prisión perpetua" que, junto con otros textos, se publicó originalmente en 1988, en el volumen titulado homónimamente Prisión perpetua. La edición definitiva, consultada para el presente artículo, es la de Anagrama (2007), integrada por dos novelas cortas: "Prisión perpetua" y "Encuentro en Saint-Nazaire". La unam reeditó Cuentos con dos rostros doce años después, en otra colección, con prólogo de Juan Villoro, pero conservando la división de los relatos.

Es palmaria la relación entre "En otro país" y "El fluir de la vida". De hecho, hacia el final del primer texto leemos que el narrador innominado dice haber escrito un relato llamado justamente "El fluir de la vida"; aún más, dentro de este segundo texto reaparecen situaciones y eventos que ya habíamos encontrado en el primero, aunque transfigurados. Este recurso intertextual es una de las marcas representativas en la obra pigliana, determinada constantemente por referencias cruzadas, por relaciones profundas entre sus distintos libros. Siguiendo a Carrión "[l]a falsificación, la copia, la fotocopia, la duplicación: en ese campo semántico hay que entender la producción pigliana"; ${ }^{1}$ esta aseveración cruza tenazmente las diversas formas de intertextualidad y alcanza incluso muchas veces lo transtextual. Tenemos, por ejemplo, a Emilio Renzi, quien recorre buena parte de su narrativa, pero podemos pensar en otros ejemplos: en el relato "La prolijidad de lo real", publicado en la revista Punto de vista en 1978, que

1 Jorge Carrión, "Dos por cuatro: la multiplicación pigliana. Prólogo", en Jorge Carrión [ed.], El lugar de Piglia. Crítica sin ficción, Barcelona, Candaya, 2008, p. 11. 
puede ser asimismo la simiente de Respiración artificial (1980); la novela corta "Encuentro en Saint-Nazaire" (1988) puede surgir no como una obra de Piglia, sino como una versión cercana a uno de los relatos creados por la máquina de Macedonio en La ciudad ausente (1992); o un personaje como Angélica Inés Echevarne, con todo y su locura, puede resultar clave en escritos diversos. En el caso particular del vínculo entre "En otro país" y "El fluir de la vida", planteo lo siguiente: como lectores nos vemos obligados a hacer una lectura diferente si se presentan como cuentos divididos, sin importar incluso que aparezcan contiguos, o si se descubren como dos partes de una misma obra. Se trata de una distinción, quizás en este caso muy sutil, entre lo que el teórico Lucien Dällenbach expone como autotextualidad (también llamada intertextualidad autárquica), esto es, de un texto consigo mismo, e intertextualidad restringida, entre dos o más textos de un mismo autor. ${ }^{2}$ Así pues, en el presente artículo analizo la relación entre "En otro país" y "El fluir de la vida" como parte integrante de la misma obra, es decir, como dos capítulos de la nouvelle "Prisión perpetua", y pretendo profundizar en las múltiples significaciones que se logran crear a través de una conexión dialógica entre ambas partes.

\section{LA PUESTA EN ABISMO}

"Prisión perpetua" ha sido estudiada y problematizada ampliamente respecto de su contenido autobiográfico. ${ }^{3} \mathrm{Y}$ es que el lector que conozca un poco de la biografía de Ricardo Piglia, se verá tentado a hacer una equivalencia entre los sucesos narrados y la propia vida del autor empírico. Aún más, elementos paratextuales abonan a esta conexión, por ejemplo, hacia el final del libro leemos en una nota: "En 'Prisión perpetua' he contado

2 Véase Lucien Dällenbach, "Intertexte et autotexte", en Poétique, núm. 26, París, 1976, pp. 282-296.

3 Hernández Peñaloza hace un recuento muy completo de la bibliografía crítica sobre lo autobiográfico en "Prisión perpetua". Véase Amor Hernández Peñaloza, "Prisión perpetua: ¿una 'autobiografía falsa' de Ricardo Piglia?", en Anuario de Letras, vol. 46, 2008, pp. 197-219. 
fragmentos de mi vida sin incurrir, confío, en la confesión sentimental ni en la autoindulgencia"; ${ }^{4}$ al término de esta acotación encontramos dos iniciales que funcionan a manera de firma: R.P. Existe otro elemento importante que no se puede soslayar ya que se encuentra dentro de la propia novela corta, una nota al pie dice: "Este relato es una versión del texto leído en abril de 1987 en el ciclo Writers talk about themselves, dirigido por Walker Percy en el Simposium Latin American Fiction Today en Nueva York". 5 Sin mayor especificación acerca de si se trata de un paratexto editorial o autoral, esta acotación cambia el sentido de la lectura. El texto que tenemos enfrente se presenta así como una reproducción de una conferencia dictada por un escritor en Nueva York. Una conferencia donde habla de su pasado, en un idioma distinto en relación con el que estamos leyendo. En la diégesis misma se acentúa la idea de una correspondencia entre lo narrado y lo factual: "De modo que ésta será una historia de deudas como todas las historias verdaderas." ¿Es acaso Ricardo Piglia, autor, cuyo nombre observamos en la portada del libro, aquel writer que en 1987 leyó un texto sobre sí mismo en Estados Unidos? Por si fuera poco, en entrevistas que se remontan a unos años antes de la publicación de "Prisión perpetua", Piglia había hablado de Steve Ratliff, personaje en torno al cual gira la narración de la nouvelle, como si se tratara de una persona real, que conoció en su juventud, tal y como se cuenta en la obra. ${ }^{7}$ José Manuel González Álvarez afirma que "[e]s de este modo como el escritor tiende una trampa con la que 'prepara' el terreno para que tres años después la crítica pueda efectuar una interpretación de 'Prisión perpetua' en clave estrictamente

Ricardo Piglia, Prisión perpetua, Barcelona, Anagrama, 2007, p. 149.

Ricardo Piglia, "Prisión perpetua", en ibid., p. 15.

Loc. cit.

Por ejemplo, en una entrevista a Carlos Dámaso Martínez de 1985, compendiada en Crítica y ficción, Piglia dice: "[...] fue una especie de maestro involuntario, por él conocí la literatura norteamericana y de un modo irónico y agresivo Ratliff orientaba mis lecturas [...] Jamás publicó un libro, sólo publicó una vez un relato en el New Yorker, pero se pasó la vida escribiendo. En la correspondencia de [Conrad] Aiken aparece varias veces". Véase Ricardo Piglia, Crítica y ficción, Barcelona, Anagrama, 2001, p. 89. 
autobiográfica". ${ }^{8}$ Esta "trampa" de Piglia parece apuntar entonces hacia un sistema de lectura en el que el autor fija el modo de recepción de su obra. Sin embargo, más allá de buscar en archivos si efectivamente la conferencia aludida en la narración fue dictada (que no lo fue, pues en realidad es una referencia apócrifa) o si Ratliff existió factualmente (en entrevistas más recientes Piglia desmintió este hecho), la idea de que nos encontramos con un texto simplemente autobiográfico irá siendo minada a través de la propia narración. La obra se irá fragmentando, disgregando, saltando entre géneros (diario, citas, aforismos) hasta que al final hallamos el texto titulado "El fluir de la vida", que se presenta como un elemento explícitamente imaginativo: un cuento escrito por el propio narrador de la parte primera de la nouvelle. Así, la única trampa consistiría en explicar la obra a la luz de una siempre incierta intencionalidad del autor. Debemos considerar que el escrito que leemos se incluye en la colección denominada Narrativas hispánicas de Anagrama, pero más allá de eso, el texto mismo irá socavando aquella posible correspondencia simple y unívoca entre, usando los términos de Dorrit Cohn, la vida histórica del autor y la vida ficcional del narrador, quien además asegura que "todas las autobiografías novelescas ofrecen un doble pacto incrustado: un pacto autobiográfico insertado al interior del pacto novelesco". 9 Lo interesante en "Prisión perpetua" es que se problematiza la relación entre ambos pactos. El lector puede poner en tela de juicio si, en este caso, la propuesta de Cohn es aplicable o si más bien existen elementos novelescos insertados al interior de un marco autobiográfico. Gracias a esta dubitación, la obra consigue crear una tensión entre realidad y ficción, que por momentos hace porosa la frontera entre ambas categorías. Para Speranza, Piglia "ha hecho de la literatura una forma condensada de autobiografía, crítica y ficción" . ${ }^{10}$ Así, la

8 José Manuel González Álvarez, En los "bordes fluidos": formas bíbridas y autoficción en la escritura de Ricardo Piglia, Berna, Peterlang, 2009, pp. 109 y 110.

9 Dorrit Cohn, "Vidas ficcionales versus vidas históricas", en María Stoopen [coord.], Sujeto y relato. Antología de textos teóricos, México, unam, 2009, p. 439.

10 Graciela Speranza, "Autobiografía, crítica y ficción: Juan José Saer y Ricardo Piglia", en Adriana Rodríguez Pérsico [comp.], Ricardo Piglia: una poética sin límites, Pittsburgh, Universidad de Pittsburgh, 2004, p. 36. 
imbricación entre lo autobiográfico y lo ficcional ampliaría y renovaría las posibilidades de la crítica literaria: "una narración que esconde un argumento crítico, un argumento crítico que se ilustra con un 'caso falso', un relato personal -autobiográfico- que expone una hipótesis crítica, una escena de un libro leído que se recupera como un recuerdo privado". ${ }^{11}$ En "Prisión perpetua", la estrategia narrativa del relato dentro del relato, aunada a la característica fragmentariedad de la obra, expone algunas de estas estrategias de crítica, de lectura y relectura.

Para Macedo Rodríguez, una cuestión fundamental en la obra

es el concepto de la dualidad y el tema del doble. Así, puede aceptarse que hay dos Piglia: el autor de Prisión perpetua y el ficcionalizado (mediante el recurso de la metalepsis), por no decir que hay dos Piglia fuera del texto estudiado: el joven que empieza a escribir su diario y por eso se convierte, años más tarde, en escritor, y el autor Piglia, que en 1988 publica la obra mencionada, en plena madurez. De la misma forma, Artigas [personaje de "El fluir de la vida"] es el doble (Doppelgânger) ficcionalizado de Ratliff, quien también pertenece a la galería de personajes imaginarios del escritor argentino. ${ }^{12}$

Esta dualidad se configura también dentro de la propia estructura de la obra a través de la exposición de un cuento en el interior de la propia nouvelle, es decir, una puesta en abismo del enunciado ficcional, también llamada por Dällenbach cita de contenido o resumen intertextual:

[...] en cuanto parte integrante de la ficción que resume, dentro de ella se hace instrumento de retorno, dando lugar, por consiguiente, a una repetición interna. No cabe pues sorprenderse de que la ficción narrativa de toda mise en abyme ficcional se caracterice fundamentalmente por la acumulación de las propiedades ordinarias de iteración y del enunciado en segundo grado; a saber: la aptitud para dotar a la obra de una estructura

12 Alfonso Macedo Rodríguez, De la crítica a la ficción y de la ficción a la crítica: una lectura sobre la poética de Ricardo Piglia, México, 2007 (Tesis de maestría, Universidad Autónoma Metropolitana-Iztapalapa), p. 84. 
fuerte y robustecer la significancia, para hacerla dialogar consigo misma, suministrándose un aparato de auto-interpretación. ${ }^{13}$

Se trata pues, como en este caso, de un relato contenido dentro del relato mismo. Así, el cuento final de "Prisión perpetua" remite a una segunda lectura de la obra donde el sentido es retroactivo. Retomo de nueva cuenta a Dällenbach, quien escribe que "[1]a mise en abyme inaugural lo dice todo antes de que la ficción llegue a arrancar de veras; la mise en abyme terminal, en cambio, no tiene nada que añadir, aparte de ir repitiendo lo ya sabido". ${ }^{14}$ No obstante, "El fluir de la vida", siendo una puesta en abismo terminal, objeta esta última aseveración. Si bien incluso el narrador afirma claramente que el relato habla sobre su amigo Ratliff: "Varias veces traté de hablar de él y de usar su legado pero recién hace un tiempo pude escribir un relato sobre Steve. No está nombrado, pero se trata de él", ${ }^{15}$ y se vale de fragmentos contenidos en la primera parte para construir la ficción, el resultado no es una mera repetición del relato marco que lo contiene. Por el contrario, el cuento expande los sentidos de la obra en su conjunto y manifiesta más de lo que ya sabíamos. Por ejemplo, se rellenan los hiatos referenciales acerca de Ratliff, que son claramente desconocidos para el narrador en la diégesis principal, a través de escenas inventadas por el propio narrador y, más aún, algunas ya no inventadas sino obtenidas de su propia vida. Por esta razón, tanto el narrador como los lectores consiguen alcanzar una mayor profundidad y complejidad interpretativa tanto del personaje Ratliff, como de la nouvelle misma. Al entreverar la historia de Ratliff con la suya propia, el narrador realiza una acción doble: rememora a su amigo, y a la vez se constituye a sí mismo a través del relato. De este modo, se intensifica la idea de que la realidad está formada tanto por narraciones imaginativas como por otras con correspondencia factual, y que la historia personal está indisolublemente entreverada con las historias de los demás. Así, el relato final aparece como un espejo no

13 Lucien Dällenbach, El relato especular, Madrid, Visor, 1991, p. 73.

14 Ibid., p. 82.

15 Piglia, "Prisión perpetua"..., p. 62. 
fiel, que más que reflejar con precisión su contraparte, la amplía, la excede, y una segunda lectura de la obra (y todas las subsiguientes) resulta más rica en significaciones. En la frase: "No está nombrado, pero se trata de él" se condensan las posibilidades de la literatura como una figuración que puede desbordar lo factual y que a la vez, precisamente por ello, es capaz de decirnos más sobre la misma realidad, aunque en otro registro, con un sentido desplazado, muchas veces metafórico, elíptico. Al mismo tiempo, estamos frente a una literatura capaz de fundar realidades al crear, reproducir, reconstruir y transformar las ficciones que circulan, individual y socialmente.

Dällenbach menciona que "[e]n cuanto segundo signo, en efecto, la mise en abyme no sólo hace que destaquen las intenciones significantes del primero (el relato que la vehicula), sino que también pone de manifiesto que éste (no) es (sino) signo y que proclama como tal un tropo cualquiera aunque con un vigor centuplicado por su tamaño: Yo soy literatura; yo, y el relato que me contiene". ${ }^{16}$ En "Prisión perpetua" la afirmación del teórico es exacta. El metarrelato ${ }^{17}$ desnuda el marco primero en el que se encuentra y lo expone como literatura también. He ahí una consecuencia fundamental que podríamos descubrir en el hecho de que "En otros país" y "El fluir de la vida" sean partes integrantes de la misma obra. Se evidencia, pues, que la apuesta de "Prisión perpetua" no pasa en exclusividad por lo autobiográfico. No obstante, tampoco se trata estrictamente de un gesto propio de la vanguardia de hacer notar que la literatura no es la vida y que los personajes no son personas. La obra se asienta en la tensión entre ambas propuestas, como se comprueba en el recorrido de la conferencia inicial y los datos autobiográficos de "En otro país", supuestamente reales, hasta desembocar en un cuento, "El fluir de la vida", tácitamente ficcional. El propio nombre del bar, Ambos Mundos, en donde el narrador y Ratliff suelen conversar y relatar, se puede leer como

16 Dällenbach, op. cit., p. 74.

17 Sigo también al propio Dällenbach en su definición de metarrelato: "segmento textual apoyado por un narrador interno a quien autor o narrador ceden temporalmente su sitio, liberándose pues de su responsabilidad de conductores del relato". Véase Dällenbach, op. cit., p. 66. 
una suerte de enunciación emblemática de la conexión autotextual entre el relato y el metarrelato, además de que "no sólo sugiere la existencia del mundo real con el de la ficción, sino también otras categorías binarias: la razón y la locura; la filosofía y la literatura; Europa y América; Estados Unidos y Latinoamérica; Buenos Aires y la (sic) Plata; Alemania y Paraguay; el exilio y la repatriación; los autores canónicos y los marginales, etcétera”. ${ }^{18}$

Encontramos, también, otro tipo de puesta en abismo, que surge como puntal en "Prisión perpetua", una que Lucien Dällenbach propone denominar de la enunciación, y entre cuyas características incluye "la "presentificación' diegética del productor o del receptor del relato", ${ }^{19}$ esto es, una exposición narrativa de personajes autores y lectores. En "Prisión perpetua", tanto el narrador como Ratliff están claramente determinados por la práctica de la escritura. Y más aún, existen segmentos donde el narrador original parece perder su voz y cedérsela a Steve, quien se convierte en el autor de los escritos que leemos. Hay otros momentos, incluso, en donde sus voces se confunden y se mezclan, y el lector no puede estar seguro de quién habla; momentos en los que el discurso directo apunta al narrador como enunciador, pero los hechos que se narran sugieren más bien que son eventos de la vida de Steve. Un ejemplo claro es un fragmento que refiere: "Mi madre fue la primera mujer que manejó un auto en el estado de Tennessee" ${ }^{20}$ Este discurso directo y en primera persona habrá que adjudicárselo a Ratliff, debido a que las marcas espacio-temporales en todo ese párrafo apuntan hacia él y no al primer narrador. Asimismo, se deben sumar los microrrelatos que surgen como ajenos a la historia de Ratliff, tramos que suelen comenzar con un "había un" y que poseen un sujeto de enunciación innominado e inidentificable. El cuento final, "El fluir de la vida", tendrá también su propio narrador, que a su vez hablará de un personaje, el Pájaro Artigas, a quien si bien no se le adjudica el ejercicio de la escritura propiamente, sí se dice de él que es un "narrador tradicional",

18 Macedo, op. cit., pp. 86 y 87.

19 Dällenbach, op. cit., p. 95.

20 Piglia, "Prisión perpetua"..., p. 29. 
en clara referencia a "El narrador", ${ }^{21}$ de Walter Benjamin. Acorde con González Álvarez, "cada uno de los personajes porta un relato que contiene otro en germen, en una libre circulación de historias que paradójicamente convierte a los emisores en reos: Lucía Nietzsche, Artigas, Steve Ratliff, Morán, el narrador y las distintas voces que concurren en la nouvelle aparecen condenados, pues, a la perpetua prisión de la enunciación". ${ }^{22}$ Así, la puesta en abismo muestra a personajes narrando a otros, quienes asimismo deberán fungir como narradores de nuevos fragmentos. Ciertamente, al interior de la obra, este procedimiento parece vinculado con un cautiverio tematizado, donde los personajes no pueden considerarse libres de la práctica del discurso; no obstante, la multiplicidad de voces trae consigo también otras implicaciones. A pesar de los distintos géneros que se evidencian en la nouvelle, existe siempre una misma enunciación tras todo esto. El lector se desliza entre ellos sin poder estar seguro, algunas veces, de saber en qué momento ha pasado de uno a otro: del relato autobiográfico a la conferencia, de allí a un diario, hasta llegar al cuento conclusivo, pasando por un sinfín de enunciados aforísticos. Entonces habría que pensar en el autor como una "función variable y compleja del discurso", 23 que busca descomponerse en una multiplicidad de voces, no a través del modo más usual u ordinario de un cambio en el registro lingüístico, sino mediante la dispersión de una posible voz narrativa preponderante y dueña única del relato. Aunado a esto, es importante mencionar el continuo uso de un discurso indirecto donde "otro dice": "El que bebe, dice Steve, intenta disolver una obsesión"; ${ }^{24}$ o donde "otro dice que alguien más dijo": "Mi padre, dijo Steve, dice que la mejor historia del mundo es la más fácil de contar". ${ }^{25}$ Esta situación permanente de darle la voz al otro no es arbitraria. Gracias a esta estrategia textual, el autor deja de jugar un rol tradicional de regulador de la ficción, pues, en palabras de Foucault, es el "rol característico de la época industrial y burguesa, del individualismo

21 Walter Benjamin, "El narrador", en Stoopen, op. cit.

22 González Álvarez, op. cit., p. 130.

23 Michel Foucault, "¿Qué es un autor?", en Stoopen, op. cit., p. 131.

24 Piglia, "Prisión perpetua"..., p. 22.

25 Ibid., p. 25 
y la propiedad privada". ${ }^{26}$ La frase "no importa quién habla" resulta una máxima que caracteriza toda la narración, al grado de que no importa siquiera si aquel que habla es un personaje perteneciente a la diégesis primaria o al metarrelato. Y así como se multiplican las voces dentro de la narración, del mismo modo proliferan las posibles interpretaciones. $\mathrm{Ni}$ el autor, ni el narrador son más una autoridad que gestiona y sistematiza los significados. La multiplicidad de voces y de géneros al interior de la obra generada por la puesta en abismo de la enunciación, se corresponde con una suerte de socialización —en la significación más amplia de la palabra-del sentido. Este continuo devenir de la enunciación convergerá en el cuento final, donde se funden y a la vez se dilatan las distintas voces, las múltiples significaciones.

\section{FRAGMENTACIÓN}

En la primera parte de "Prisión perpetua", tras aquella narración de tipo autobiográfico, encontramos segmentos de un diario que irán disgregándose, perdiendo primero la fecha en la cual fue escrito cada uno y conservando en cambio frases que sirven a manera de subtítulos: La idea fija, La mujer del párroco, La voz cantante... Aquellos nombres desaparecerán, los párrafos se acortarán hasta llegar a enunciados más bien aforísticos. Los siguientes pasajes, aunque no tendrán una estructura similar, conservarán esta característica fragmentariedad: será un vaivén entre, por un lado, la historia referente a Ratliff y, por el otro, los microrrelatos que parecen, de entrada, poco tener que ver entre sí. En la segunda parte de la nouvelle, es decir, en el cuento titulado "El fluir de la vida", se narra la historia de amor entre el Pájaro Artigas y Lucía Nietzsche. En el presente de la narración, Lucía está recluida en una clínica psiquiátrica y a Artigas no le queda más que rememorar y narrar una y otra vez el verano que pasaron juntos, así como diversos sucesos determinantes en su relación. Encontramos, por ejemplo, fragmentos de la vida de Lucía Nietzsche, quien dice ser

26 Foucault, op. cit., p. 132. 
descendiente del filósofo alemán del mismo apellido; el posible suicidio de su madre; las fotografías increíbles que el padre de Lucía tomaba maniáticamente de su mujer; la locura con la que la propia Lucía se caracterizaba a sí misma; y diversas anécdotas que Lucía decía tomar de unas cartas que había encontrado en su armario; cartas escritas por gente del barrio y dirigidas a Eva Perón. Si bien se trata nuevamente de una proliferación de historias, esta serie de pasajes y acontecimientos está conformada por la montura de personajes, situaciones y escenarios dispersos en la parte anterior de "Prisión perpetua", pero que ahora surgen con una unidad de sentido. La sobrina de Nietzsche, la anécdota de la mujer muerta fotografiada en diversas posiciones, la idea del matrimonio como institución criminal, entre otros, se asomaban, pues, como aquellos fragmentos ajenos a la narración nuclear en "En otro país" y son retomados en "El fluir de la vida" para referirse a Steve Ratliff, quien encontraría en la historia del Pájaro Artigas su propia historia metaforizada. En los pasajes fragmentarios los personajes se multiplican, los párrafos se acortan y el lector se queda con una serie de viñetas, en apariencia disímiles y desconectadas entre sí. No obstante, el continuo uso de "Había un / Había una" como inicio de párrafo marca una conexión sintagmática entre los segmentos, y de alguna forma evoca el principio de los cuentos tradicionales, donde el autor original (si es que se puede hablar de autoría en un cuento popular) se pierde en el tiempo y, dado que comúnmente se transmiten de manera oral, las variantes se multiplican, por lo que podemos pensar en una narración distinta durante cada enunciación de un mismo relato. Pero en contraste con cierto tipo de cuento tradicional, los microrrelatos en la obra se manifiestan ajenos a un veredicto ético o a alguna traza de moraleja; la misma falta de comentarios o juicios valorativos por parte de los personajes acerca de estos fragmentos provoca una lectura inestable. Más que pensar que dicha indeterminación impele al lector a asumir el papel de juez, considero que promueve una vacilación, una descolocación de los propios criterios. En la obra, el lector oscila entre atribuir los susodichos tramos breves a menciones de Ratliff, a apuntes del narrador primario o simplemente a mensajes de un narrador innominado; aunque más bien habría que hablar de múl- 
tiples narradores innominados y anónimos, quienes en algún momento fijaron alguna versión de los eventos que cuentan. A pesar de lo disímil que puede resultar cada uno de esos sucesos, en uno de aquellos microrrelatos encontramos encubierta una posible clave de lectura. Se trata de la historia de un falso psiquiatra, instalado en Nueva York, que atiende un sitio de asistencia al suicida y que está interesado exclusivamente en grabar las conversaciones para escucharlas una y otra vez, para llegar al acontecimiento definitorio, determinante, que tenían a sus interlocutores al borde del suicidio. El conjunto de todas aquellas conversaciones compondría "el centro de la obsesión secreta de Nueva York". ${ }^{27}$ La obra propondría entonces un movimiento paralelo: la serie misma de microrrelatos se podría leer como un mismo relato heterogéneo y complejo. Cada fragmento no sería sino una variante de un mismo cuento, uno que estaría en constante circulación, rectificación y ampliación. Una historia de las obsesiones, pesadillas y vivencias de una sociedad; un retrato en continua mutación que abarcaría no sólo la realidad más palpable, sino además el submundo inconsciente y vedado. Lo interesante es que la obra misma, a través del cuento final, nos mostraría una de las versiones, una concretización escritural de ese hipotético cuento en continua mutación y ajuste. Siendo así, el relato que, como se ha dicho, habla de Steve sin tener que nombrarlo, también podría estar hablando no sólo de la neoyorquina, sino de cualquiera de las sociedades modernas, sin necesidad de designarlas de manera específica. Urbes con claras directrices carcelarias, donde el crimen se ha vuelto moneda corriente y donde elementos propios del sistema penitenciario tales como la paranoia, los pensamientos circulares, la repetición paralizante, la incomunicación, el individualismo y el aislamiento se han extrapolado hasta alcanzar a la sociedad toda.

Lo carcelario es, sin duda, uno de los aspectos cardinales de "Prisión perpetua", expuesto ya desde el título de esta novela corta. Foucault, en su emblemática obra Vigilar y castigar, asegura que "[l]a soledad es la condición primera de la sumisión total" ${ }^{28}$ de allí que el penal tenga

27 Piglia, "Prisión perpetua"..., p. 46.

28 Michel Foucault, Vigilar y castigar, México, Siglo XXI, 2009, p. 273. 
dispuesto el espacio de modo que la única comunicación posible sea vertical, jerárquica: las órdenes que el guardia dirige hacia los presos. La incomunicación funcionaría como la raíz de la soledad y también como el corolario último donde se busca que el preso obedezca en silencio. Presos que, además, pierden su singularidad, y se constituyen en masa homogeneizada. Esta indiferenciación provocada premeditadamente por el sistema penitenciario tiene como objetivo el control de los bandos opositores o discrepantes, al criminalizarlos. Retomo de nuevo a Foucault, quien manifiesta que "la prisión no puede dejar de fabricar delincuentes. Los fabrica por el tipo de existencia que hace llevar a los detenidos: ya se los aísle en celdas o se les imponga un trabajo inútil"; ${ }^{29}$ el aislamiento y con él la incomunicación serían entonces dos de los principales factores con los que la red de prisiones efectivamente fabrica delincuentes, al minar los mecanismos necesarios para una posible y efectiva reinserción social. En la nouvelle, la cárcel es vista, de hecho, como una institución educativa o, más precisamente, de amaestramiento, que abarca todos los aspectos de la vida, y que busca extenderse, incluso, al abandonar la penitenciaría; así lo leemos: "Una educación integral, sistemática: física, cerebral, psíquica, moral, filosófica, muscular, óptica, sexual. Se enseñan nuevas relaciones con el tiempo, otra relación con el lenguaje y la obediencia". ${ }^{30}$ La breve y monótona marcha circular que un prisionero puede hacer dentro de su celda se repite al salir, alcanzando también sus pensamientos, intenciones y decisiones. Por ejemplo, hallamos a un ex presidiario que tras haber estado encerrado en una cárcel por años se dirige hacia Nueva York y una vez que ha llegado habla con su esposa en estos términos: "quiero decir que es absolutamente necesario que posterguemos todo lo referente a nuestros amores personales y empecemos enseguida a pensar en planes específicos de trabajo y realización económica. Y así sucesivamente, contó Steve, con el recorrido circular de quien ha estado en prisión" ${ }^{31} \mathrm{El}$ personaje se ha librado entonces de una prisión sólo para entrar en otra;

30 Piglia, "Prisión perpetua"..., p. 47.

31 Ibid., pp. 24 y 25. 
sus ideas y sus movimientos siguen atados, ahora, a la idea de un triunfo monetario. El periodo pasado en la cárcel ha moldeado sus acciones y lo sigue condicionando una vez en el exterior.

Más adelante leemos: "Adentro no hay otra conexión con el mundo que el graznido de la televisión encendida durante horas para todo el penal"; ${ }^{32}$ de esta manera, la difícil comunicación entre los presos se vuelve por completo impracticable con el ámbito exterior. Un aparato invariablemente encendido, que no transmite más que sonidos vacuos y fútiles, y un recluso como simple receptor de ellos, sin posibilidad de responder $\mathrm{u}$ objetar nada de lo que oye: ésa es la dinámica carcelaria que la obra nos exhibe. Ante esto, no parece difícil concebir que varios de los personajes que han estado presos, al salir de prisión no logran entender la realidad exterior. Lo de afuera es siempre excesivo en relación con las limitaciones carcelarias, son incapaces de interpretar el mundo. Cito, por ejemplo, el caso de otro ex presidiario: "Afuera tuvo la impresión de que la realidad tenía la banda de sonido mal sincronizada. Parecían querer decirle algo que no entendía. Todo se cargaba de un sentido múltiple; las relaciones entre acontecimientos dispersos eran excesivas. Trataba de descifrar únicamente los mensajes que le estaban personalmente dirigidos. "33 La prisión se presenta como una institución que intenta reducir al preso a ser un rígido consignatario de mandatos a través de una semántica árida y escueta, donde el pragmatismo se verifica en el cumplimiento estricto de las órdenes. Tras un acondicionamiento de este tipo, algunos personajes pierden la capacidad de leer el mundo exterior: la cantidad de signos que el afuera les envía es para ellos exorbitante. El vacío experiencial del presidio los ha marcado indisolublemente. En "Prisión perpetua" la cárcel es un laboratorio aciago, y tiene como objetivo primordial observar "cómo reacciona un individuo cuando se lo priva por completo de experiencias durante un tiempo prolongado". ${ }^{44}$ Precisamente esa falta de experiencias estaría manifestada en la primera parte de la obra a través de huecos narra-

$\begin{array}{ll}32 & \text { Ibid., p. } 48 . \\ 33 & \text { Loc. cit. } \\ 34 & \text { Ibid., p. } 32 .\end{array}$ 
tivos: lo que no se nos cuenta sobre aquellos presos. Los blancos entre fragmento y fragmento podrían pensarse como una representación de las paredes que separan y aíslan a los reclusos entre sí. De este modo, en la nouvelle, los procedimientos estructurales que apuntan hacia lo carcelario impulsan a que el lector entre de lleno en el universo ficcional de los personajes. El tránsito a través de esta parte de la obra no puede ser sino errático, sospechoso, fragmentario y contingente, porque ése es el espacio que se encuentra representado.

En el cuento final, la estrategia es distinta. Una de las varias historias transfiguradas dentro del metarrelato es el caso de un asesino; en "En otro país", apenas nos enteramos de los acontecimientos a partir del contenido de una nota informativa:

Un padre. Encontré en el diario una historia que vale la pena, dijo hoy Steve. Un tipo había matado a su mujer y a su hija menor y había enterrado los cuerpos en los fondos del club donde trabajaba de jardinero. Tapó el arma con una almohada para no verle la cara a su hija y ahogar el ruido. En su descargo dijo que estaba convencido de que su mujer era una prostituta y no quería que su hija siguiera el mismo camino. ${ }^{35}$

Tras este breve párrafo no volvemos a encontrar nada más sobre el caso en la primera parte de la nouvelle. En el cuento final, "El fluir de la vida", descubrimos, asimismo, aquella historia del padre asesino, pero ampliada y transfigurada, de modo que rebasa lo que en un principio se exhibía como una simple nota periodística. Y aunque dentro de la lógica diegética lo narrado en el cuento no es verificable con los lacónicos hechos hallados en la nota del diario, lo importante parece ser que se reconoce en el personaje una existencia más allá de su crimen. Para empezar se le da un nombre: Aldo Reyes, y se le otorga una voz: en el cuento él mismo refiere su historia, sus pensamientos y reflexiones, los cuales no necesariamente están en relación con el asesinato que cometió. Él es un criminal, pero también es más que eso. Y resulta, sin duda, muy significativo que este personaje se presente como un lector asiduo de la historia

35 Ibid., p. 26. 
argentina y casi como un profeta, que augura un destino violento y sangriento para toda la nación; el preso, el asesino, como símbolo del futuro de una sociedad. En "El narrador", Benjamin contrapone "información" con "narración" al hablar sobre el novelista ruso Lesskow, y expone que cada uno de sus lectores "es libre de arreglárselas con el tema según su propio entendimiento, y con ello la narración alcanza una amplitud de vibración de que carece la información". ${ }^{36}$ En el caso que nos ocupa, lo que aparecía como un sencillo apunte informativo, favorece el ideal del sistema penitenciario al reducir y constreñir la existencia de aquel asesino a su delito; por su parte, el cuento final, epítome de lo literario, lo desborda. El lector reconoce entonces a un personaje complejo y con múltiples ángulos, donde el crimen, acaso, no sea más que una consecuencia de la lógica social en la que se encuentra sumido. Y que todo esto se haga expreso, no en el nivel diegético principal, sino a través del metarrelato, que se presenta como algo expresamente fictivo, pone de manifiesto que lo literario puede alcanzar dominios que una sociedad carcelaria prefiere omitir. De este modo, en cada fragmento, el lector deberá imaginar las posibles historias debajo: "lo que no está dicho", y a partir de eso se vuelve insostenible hallar una definitiva y única resolución. Distintas versiones, distintas verdades para cada relato, para la nouvelle, e incluso para la realidad misma.

Un evento de la historia argentina insertado hacia la mitad de la obra, destaca por la aparente poca relación con el resto de lo narrado. Tras descomponerse el auto en el que viajaban, el narrador y otro personaje, de nombre Morán, se ven obligados a hacer una parada en un pueblo. Allí, observan la inmensa zanja cavada en 1876, ordenada por Adolfo Alsina, ministro de Guerra, en un intento de contener los malones. ${ }^{37}$ José Luis Romero escribe que en aquella época "[u]na vasta región del país estaba de hecho al margen de la autoridad del Estado y bajo el poder de los ca-

36 Benjamin, op. cit., p. 38.

37 Se trata de incursiones sorpresivas y veloces por parte de indígenas a caballo, en Argentina y Chile durante el siglo XIX, especialmente con el fin de saquear estancias y hurtar provisiones. 
ciques indígenas que desafiaban las fuerzas nacionales"; 38 la construcción de aquella especie de "Muralla China subterránea", como es llamada en la obra, fue finalmente inútil porque los indios lograban saltarla montados en sus raudos caballos. Esta zanja estructural, además de funcionar como un recurso de tensión narrativa, señala un intento de marginar a aquellos indígenas, a quienes se intentaba vedar el acceso a un centro. Un destierro dentro del propio territorio es lo que está en juego en la crónica histórica. La zanja como otra forma de muralla; el confinamiento como otro modo de prisión. Fornet, al discurrir respecto a la literatura de Piglia en general, indica: "La digresión es, en fin, una estructura que permite eludir lo que debería ser el tema central de la novela, y se convierte, ella misma, en columna vertebral." ${ }^{\text {39 }}$ Este planteamiento se hace especialmente evidente en "Prisión perpetua" con la proliferación de historias, caracterizadas por una constante fragmentariedad, surgida algunas veces por una marcada tendencia hacia la oralidad. No omito señalar que en la narración se sugiere la idea de que la nouvelle misma está basada en una conferencia; de este modo, la palabra hablada debe ser señalada como un registro constante, si bien encubierto: se trata de un texto escrito que, sin embargo, simula haber sido leído originalmente en voz alta, frente a una audiencia en vivo, y de ahí que conserve ciertas marcas orales, por ejemplo: "ya oirán ustedes los ritmos de la prosa de mi juventud", ${ }^{40}$ dice el narrador. Esta confluencia de elementos - digresión, fragmentariedad, oralidad - apunta hacia una estructuración de la obra que, más que aplazar el arribo al centro de la narración, apuesta por un descentramiento, donde habrá no uno sino diversos puntos focales, todos valiosos para descifrar los también múltiples sentidos en la obra. Gracias a esto se subvierte la idea de un solo núcleo temático o semántico, capaz de aislar o excluir a quienes pueden o no llegar a él.

38 José Luis Romero, Breve historia de la Argentina, Buenos Aires, FCE, 2013, p. 99.

39 Jorge Fornet, El escritor y la tradición en la obra de Ricardo Piglia, México, 2000 (Tesis de doctorado, El Colegio de México), p. 12.

40 Piglia, "Prisión perpetua"..., p. 18. 
La rememoración diegética de los hechos en esta obra pigliana nos traslada hacia mediados del siglo pasado, donde la dictadura argentina del 55 y la sociedad estadunidense de los mismos años dejan de ser sólo un aparente fondo para la narración y reconocemos en ellas una realidad social que surge a partir de la infinidad de relatos que la recorren, muchos de los cuales son provenientes de un poder, como sería un estado dictatorial en Argentina o el macartismo en Estados Unidos, el cual tendería a crear una atmósfera cuyas marcas predominantes serían la locura, la opresión, el miedo, la persecución, la pérdida de la experiencia. Cabe recordar que "Prisión perpetua" fue publicada en 1988, apenas cinco años de terminada la dictadura y muy poco tiempo después de la aprobación de la Ley de Punto Final y la Ley de Obediencia Debida, con las cuales se detuvieron los juicios contra los militares, e implícitamente se adoptaba una posición política basada en el olvido. Es claro que las medidas tomadas en todos los órdenes durante el autodenominado Proceso de Reorganización Nacional continuaron repercutiendo en la vida de los ciudadanos. El modelo neoliberal de los noventa tiene sus antecedentes en las pautas económicas de la junta militar; una nueva dictadura, la del Mercado, no necesita más de un Videla, pero sigue haciendo uso de buena parte de aquellos mitos legitimadores y del sistema penitenciario. Y así como ya se ha dicho que el cuento final en "Prisión perpetua" habla de Steve sin tener que nombrarlo, la nouvelle misma alcanza un rango de máxima significación al poder hablar también críticamente de su contexto a través de un desplazamiento a veces temporal -otra dictadura, la del 55-, a veces también geográfico - Nueva York en la década de los cincuenta-. Con todo, somos nosotros, los receptores de la obra, quienes podremos ampliar aún más su campo interpretativo al encontrar en ella, por ejemplo, una exploración de nuestras propias prisiones, o reconocer que nuestra existencia, más allá de verdades unívocas y privativas, se constituye por un entramado siempre múltiple y complejo. 
BIBLIOGRAFÍA

Benjamin, WaLter, "El narrador", en María Stoopen [coord.], Sujeto y relato. Antología de textos teóricos, México, unam, 2009, pp. 33-54.

CARRIÓn, JoRge, "Dos por cuatro: la multiplicación pigliana. Prólogo", en Jorge Carrión [ed.], El lugar de Piglia. Crítica sin ficción, Barcelona, Candaya, 2008, pp. 9-23.

COHn, DORRiT, "Vidas ficcionales versus vidas históricas", en María Stoopen [coord.], Sujeto y relato. Antología de textos teóricos, México, UNAM, 2009, pp. 421-444.

DällenbaCh, Lucien, "Intertexte et autotexte", en Poétique, núm. 26, París, 1976, pp. 282-296.

, El relato especular, trad. de Ramón Buenaventura, Madrid, Visor, 1991.

FoRNET, JORGE, El escritor y la tradición en la obra de Ricardo Piglia, México, 2000 (Tesis de doctorado, El Colegio de México).

FouCAult, Michel, “Qué es un autor?”, en María Stoopen [coord.], Sujeto y relato. Antología de textos teóricos, México, unAM, 2009, pp. 113-132. , Vigilar y castigar, trad. de Aurelio Garzón del Camino, México, Siglo XXI, 2009.

GONZÁLEZ ÁLVAREZ, JosÉ MANuEL, En los “bordes fluidos”: formas bíbridasy autoficción en la escritura de Ricardo Piglia, Berna, Peterlang, 2009. HERNÁNDEZ PeÑalOZA, Amor, "Prisión perpetua: ¿Una 'autobiografía falsa' de Ricardo Piglia?", en Anuario de Letras, vol. 46, 2008, pp. 197-219. MACEDO RODRÍGUEZ, ALFONSO, De la crítica a la ficción y de la ficción a la crítica: una lectura sobre la poética de Ricardo Piglia, México, 2007 (Tesis de maestría, Universidad Autónoma Metropolitana-Iztapalapa). Piglia, Ricardo, Crítica y ficción, Barcelona, Anagrama, 2001. , Cuentos con dos rostros, México, UnAM, 1992 (Coordinación de Literatura). , Nombre falso, Buenos Aires, Siglo XXI, 1975. Buenos Aires, Seix Barral, 1994. Barcelona, Anagrama, 2002. , Prisión perpetua, Barcelona, Anagrama, 2007. 
Romero, José LuIs, Breve historia de la Argentina, Buenos Aires, FCE, 2013.

SPERANZA, GRACIELA, "Autobiografía, crítica y ficción: Juan José Saer y Ricardo Piglia", en Adriana Rodríguez Pérsico [comp.], Ricardo Piglia: una poética sin límites, Pittsburgh, Universidad de Pittsburgh, 2004, pp. 29-40. 
